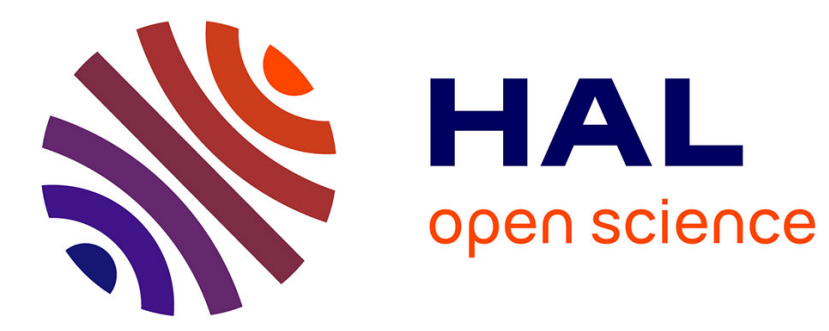

\title{
Measurement of Low Frequency Impact Insulation
}

John Loverde, Wayland Dong, Sunit Girdhar

\section{To cite this version:}

John Loverde, Wayland Dong, Sunit Girdhar. Measurement of Low Frequency Impact Insulation.

Forum Acusticum, Dec 2020, Lyon, France. pp.1639-1642, 10.48465/fa.2020.0889 . hal-03231795

\section{HAL Id: hal-03231795 \\ https://hal.science/hal-03231795}

Submitted on 21 May 2021

HAL is a multi-disciplinary open access archive for the deposit and dissemination of scientific research documents, whether they are published or not. The documents may come from teaching and research institutions in France or abroad, or from public or private research centers.
L'archive ouverte pluridisciplinaire HAL, est destinée au dépôt et à la diffusion de documents scientifiques de niveau recherche, publiés ou non, émanant des établissements d'enseignement et de recherche français ou étrangers, des laboratoires publics ou privés. 


\title{
Measurement of Low-Frequency Impact Insulation
}

\author{
John LoVerde ${ }^{1} \quad$ Wayland Dong $^{1} \quad$ Sunit Girdhar $^{2}$ \\ ${ }^{1}$ Veneklasen Associates, Santa Monica, California, USA \\ ${ }^{2}$ Michigan Technological University, USA \\ wdong@veneklasen.com
}

\begin{abstract}
The measurement of low frequency impact sound in rooms (below $100 \mathrm{~Hz}$ ) is critical to determining human response and acceptability of floor ceilings [1], [2]. Measurement uncertainties generally increase at lower frequencies, and a lack of precision is a general problem that ratings of low-frequency noise must overcome. Impact noise uncertainties at low frequencies are reviewed. The effect on measurement uncertainty of changes to the measurement procedure (such as fixed vs. roving microphones, measurement duration, microphone position, number of tapping machine locations, etc.) is studied, with emphasis on the uncertainties in the $50-80 \mathrm{~Hz}$ third-octave bands. The measurement uncertainty will be related to the precision desired to accurately relate to human reaction.
\end{abstract}

\section{INTRODUCTION}

Impact noise insulation currently evaluated using Impact Insulation Class (IIC) per ASTM E989 [3] or $\mathrm{L}_{\mathrm{n}, \mathrm{w}}$ per ISO 717-2 [4], based on measured impact sound pressure levels from a standard tapping machine. These ratings are calculated from the impact noise level measured in thirdoctave bands from 100-3150 Hz. As ASTM E989 states, the existing impact noise ratings do "not deal with low frequency sounds below $100 \mathrm{~Hz}$ that are typically generated below lightweight joist floors when they are walked on" [3, p. 989].

There is broad agreement that frequencies below $100 \mathrm{~Hz}$ are important for evaluating human reaction [2]. The authors have defined a new rating for measuring low-frequency impact isolation in the field called Low-frequency Impact Rating (LIR) [1], [5]. This rating is calculated by

$$
L I R=190-2 L_{50-80}
$$

where $L_{50-80}$ refers to the energetic sum of the impact sound pressure levels in the 50,63 , and $80 \mathrm{~Hz}$ thirdoctave bands.

ISO 717-2 [4] includes spectrum adaptation terms, one of which $\left(\mathrm{C}_{\mathrm{I}, 50-2500}\right)$ extends the lower limit of measurement from $100 \mathrm{~Hz}$ to $50 \mathrm{~Hz}$. This rating $L_{n T, w}^{\prime}+C_{I, 50-2500}$, abbreviated $L_{n T, 50}^{\prime}$, was the rating chosen in COST Action TU0901 to express the guideline impact classifications.[2] That document states that that this metric is used as it "has emphasis on low frequencies as this is more relevant for subjective assessment."
Therefore, there is the need to measure impact sound down to (at least) the $50 \mathrm{~Hz}$ third-octave band. However, there are many difficulties associated with measuring such frequencies, especially in relatively small rooms such as those in residences. The sound fields are not diffuse, and the strong modal character of the rooms creates difficulty in measuring and even defining the noise field. The vibration fields in some of the structures of the assembly are also modal and not diffuse.

Measurement uncertainties generally increase at low frequencies. ISO 12999-1 [6] reports the in situ standard deviation (when different teams measure the same assembly) increasing steadily as the frequency decreases, to $3.2 \mathrm{~dB}$ in the $50 \mathrm{~Hz}$ band. Similarly, gauge repeatability and reproducibility studies conducted by the authors found that the uncertainty in the impact noise measurement method increased with decreasing frequency up to about $2.5 \mathrm{~dB}$ standard deviation at $50 \mathrm{~Hz}$ [7]. Since the LIR rating in Eqn. (1) includes a factor of two in the calculation, this corresponds to an uncertainty in LIR of at least 5 to 6 points, which is unacceptably large for many uses.

Note that the factor of two in Eqn. (1) is not arbitrary but based on the properties of human perception of low frequency sound. Because the equal loudness contours are closer together at low frequencies than high, a comparatively smaller change in level results in a larger change in loudness [1], [5]. This is quite a general phenomenon not restricted to impact or footfall noise. For example it has been demonstrated and applied to ground-borne noise from trains [8]. In other words, the factor of two in the calculation method accurately describes the properties of human hearing. The measurement method needs to have lower uncertainty at low frequencies than at higher frequencies to maintain the same relative precision.

Since the uncertainty in measurement and the human sensitivity to changes in level both increase at low frequencies, it is more important to reduce the uncertainties at the low frequencies than in any other frequency range. It is therefore important to quantify the uncertainty of each aspect of the uncertainty budget. Identification of the largest sources of uncertainty will provide targets for potential changes to the measurement method that will reduce the uncertainty.

In this talk, we examine the uncertainty related to the position of the tapping machine on the floor to be tested. 


\section{EFFECT OF TAPPING MACHINE POSITION}

For field testing, ASTM standard E1007 specifies that the tapping machine be used in four specific orientations in the approximate center of the floor. These orientations defined in the standard are shown in Figure 1. There is some ambiguity in the positions; position 3 can be on either side and position 4 can be in four locations. In homogeneous slabs, there is an additional rotation available.

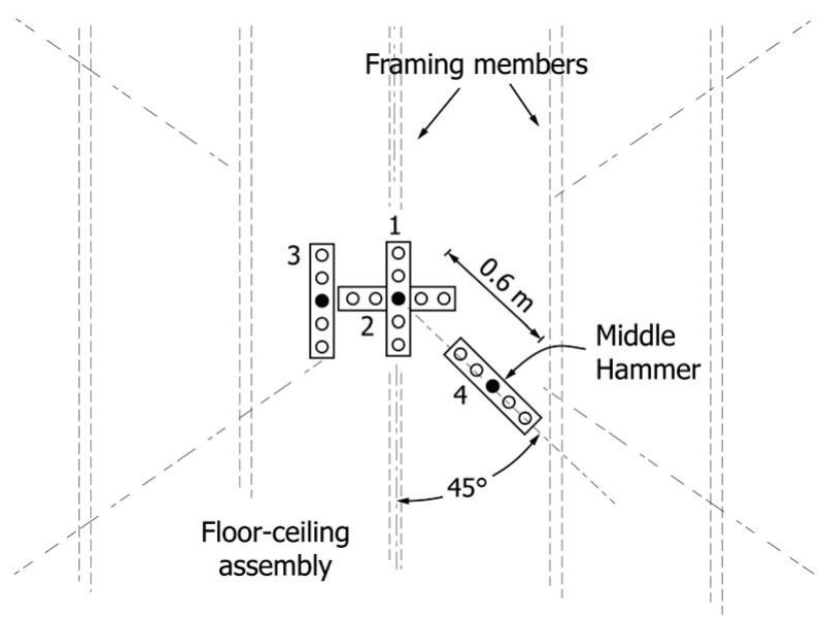

Figure 1: Tapping machine positions per ASTM E1007

ISO 16283-2 [12] also describes impact noise testing in the field. The ISO standard specifies at least four tapping machine locations randomly distributed on the assembly at least $0.5 \mathrm{~m}$ away from the edges of the floor. For anisotropic construction, the line of the hammers is to be at 45 degrees to direction of the floor joists or members. It does not specify any requirements for the orientation of the tapping machine for homogenous structures. The ISO method therefore allows greater freedom to the operator regarding the location of the tapping machine.

\subsection{Previous Studies}

The authors have presented two studies [9], [10] on the effect of tapping machine position. These studies focused on the effects of number of tapping machine positions that are averaged. Those studies did not include frequencies below $100 \mathrm{~Hz}$, and did not examine tapping positions beyond the four defined in the ASTM standard.

Larsson et al. published a study on the effect of tapping machine position relative to the joists in a wood joist floor [11]. For the floor tested, they found that when the tapping machine was placed on the joists, the sound level was 4-7 dB higher than when it was placed on the subfloor between the joists. Note that this floor was a single layer of $22 \mathrm{~mm}$ particle board glued and screwed to the joists, and did not incorporate a concrete screed as is typical in North America. A concrete screed would presumably distribute the force more evenly over the floor, and we would naively expect a reduction in this effect.
Using the ASTM standard tapping machine positions, two of the positions are directly above a joist and two are between the joists. The previous studies [9], [10] did not identify any systematic differences between the tapping machine positions. However, those studies did not examine the bands below $100 \mathrm{~Hz}$, while Larsson et al. observed this effect only below $100 \mathrm{~Hz}$.

\subsection{Wood Joist Floors}

A study was performed in the living room of an apartment building. The tested assembly was composed, from the top down, of luxury vinyl plank flooring on $25 \mathrm{~mm}$ thick gypsum concrete screed on 6 $\mathrm{mm}$ (1/4-inch) sound mat on plywood sheathing, solid wood joists (nominal 2 × 12 inches or about $290 \mathrm{~mm}$ deep) with fiberglass batt insulation, resilient channel and one layer of $19 \mathrm{~mm}$ (3/4-inch) constrained layer damped gypsum board. The source and receiving rooms were $7.6 \times 3.9 \times 2.7 \mathrm{~m}$. The rooms were unfurnished.

Nine positions for the tapping machine were established on the floor. The orientation of the tapping machine was parallel to the short dimension of the room in all cases, which is parallel to the joists. For each position, the sound pressure level was measured by scanning the room using a Bruel \& Kjaer 2270 sound level meter.

The repeatability was first estimated by measuring four consecutive times with the tapping machine in the same position. Then the sound level was measured for each tapping machine location. The standard deviation of the nine positions in shown in Figure 2 along with the repeatability.

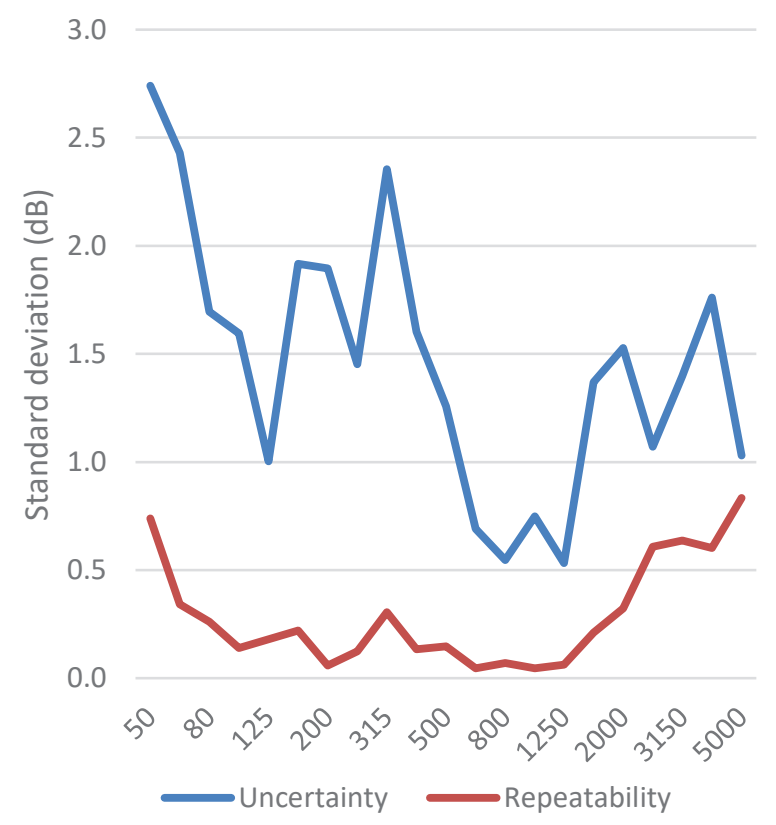

Figure 2: Standard deviation of impact noise spectra with change in tapping machine position. The repeatability of the measurement is also shown for reference.

Direct comparison to the Larson et al. study, it is not possible because it was not known when the 
tapping machine was on or between joists. The magnitude of the effect of position at the low frequencies is of a similar order to that measured by Larson et al. However, we also observed large variations in the mid and high frequencies, which was not noted in Larson et al.

\subsection{Concrete Floor}

The tested assembly was composed of precast hollow core concrete planks, $1500 \mathrm{~mm}$ wide, $100 \mathrm{~mm}$ thick with $50 \mathrm{~mm}$ diameter holes at $100 \mathrm{~mm}$ on center, with a $65 \mathrm{~mm}$ thick concrete topping slab with a thin painted waterproof coating. The receiving room was an office with dimensions were $3.7 \times 3.3 \times 3.0 \mathrm{~m}$. The walls were gypsum board on steel studs, the ceiling was the exposed concrete planks, and the floor finish was carpet tile on concrete. The room was furnished with built in office furniture. No reverberation normalization was performed.

A grid of nine tapping machine positions were established. For each tapping position, the tapping machine was tested in three different orientations $\left(0^{\circ}\right.$, $45^{\circ}$, and $\left.90^{\circ}\right)$. The mean and standard deviation of all positions and orientations is shown in Figure 3.

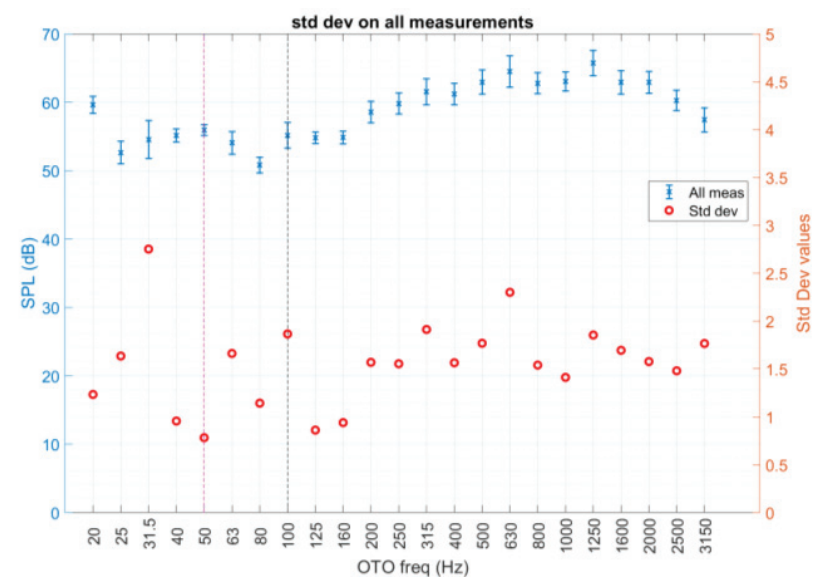

Figure 3: Mean (blue crosses) and standard deviation (whiskers, and red squares plotted on the right axis)

Direct comparison is not possible since a different set of tapping machine positions was used, but the concrete assembly, despite lacking a joist structure, has a similar range of variation as the wood joist floor. In our previous study [9], we also observed no systematic difference between wood joist and concrete floors. This implies that the variation is not attributable to the tapping machine being on or between the joists.

\subsection{Averaging}

The standards allow operators to place the tapping machine in different locations, which will result in different sound pressure levels in the receiving space. This allowed variation in tapping machine position is a source of uncertainty in the measurement. To quantify this effect, a Monte Carlo simulation was performed based on the tapping machine locations on the concrete floor described above.

For each trial, four positions were selected at random from the nine positions, and an orientation was randomly selected for each position. The single number ratings were calculated per the standard, and the process was repeated for 5000 trials. The results give the probability distribution of the rating based only on the uncertainty in tapping machine position. As an example, the distribution of $L_{n, w}^{\prime}+C_{I, 50-2500}$ is graphed in Figure 4.

Similar analyses were performed with ASTM testing on the same floor. There is less ambiguity in the tapping machine position (i.e., fewer possibilities for the four positions) in the ASTM method, so smaller variation is expected. The standard deviations of the various ratings are shown in Table 1 . They are smaller for the ASTM method, but only slightly. They are also similar between the traditional frequency range (100$3150 \mathrm{~Hz}$ ) and with the extended low frequency range.

\begin{tabular}{cc}
\hline Rating & $\begin{array}{c}\text { Standard } \\
\text { Deviation }\end{array}$ \\
\hline$L_{n, w}^{\prime}$ & 0.64 \\
\hline$L_{n, w}^{\prime}+C_{I, 50-2500}$ & 0.64 \\
\hline IIC & 0.46 \\
\hline LIR & 0.55 \\
\hline
\end{tabular}

Table 1: Results of Monte Carlo analysis showing the standard deviation of the probability distribution of single number ratings. This is the uncertainty in the rating attributable to the ambiguity in the location of the tapping machine on the floor.

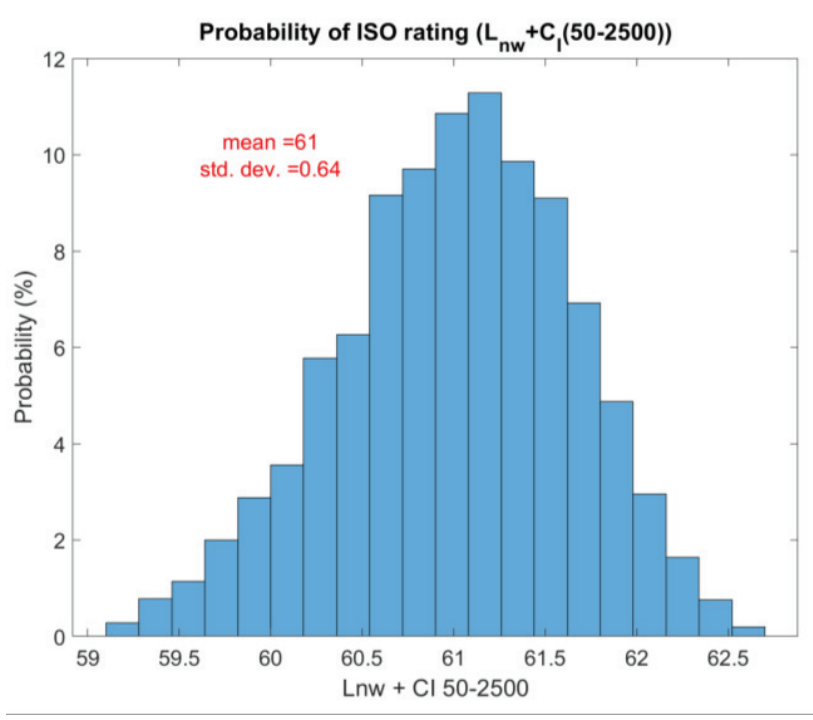

Figure 4: Results of the Monte Carlo analysis showing the probability distribution of the single number rating $L_{n, w}^{\prime}+C_{I, 50-2500}$.

\subsection{Summary}

The variations between individual tapping machine positions are surprisingly large. However once averaged per the standard, the result variation was small, with a standard deviation of less than $1 \mathrm{~dB}$. Recall that the overall uncertainty in the measurement 
at these frequencies is a standard deviation of over 2 dB.

Additional study is needed on other assembly types, and it may be possible to further reduce the uncertainty by changing how the tapping machine locations are specified or increasing the number of positions.

This suggests that the tapping machine position is not a dominant component in the uncertainty budget.

\section{ACKNOWLEDGEMENTS}

The authors would like to thank their colleagues at Veneklasen Associates for their support. We also acknowledge the assistance of Sinja Schmid and Berndt Zeitler of the Stuttgart University of Applied Sciences. Partial funding for this work was provided by the Paul S. Veneklasen Research Foundation.

\section{REFERENCES}

[1] J. J. LoVerde and D. W. Dong, "A dual-rating method for evaluating impact noise isolation of floorceiling assemblies," J. Acoust. Soc. Am., vol. 141, no. 1, pp. 428-440, Jan. 2017, doi: 10.1121/1.4973868.

[2] B. Rasmussen and M. Machimbarrena, "COST Action TU0901 - Building acoustics throughout Europe. Volume 1: Towards a common framework in building acoustics throughout Europe," COST Office Action TU0901, 2014.

[3] "ASTM Standard E989-06, Standard Classification for Determination of Impact Insulation Class (IIC)," ASTM International, 2006.

[4] "ISO 717-2 (2013), Acoustics - Rating of sound insulation in buildings and of building elements Part 2: Impact Sound Insulation," International Standards Organization, 2013.

[5] J. LoVerde and W. Dong, "A new metric to quantify and evaluate low frequency impact noise," Melbourne, 2014.

[6] "ISO 12999-1:2020 Determination and application of measurement uncertainties in building acoustics - Part 1: Sound insulation," International Standards Organization.

[7] J. LoVerde and W. Dong, "Gauge repeatability and reproducibility studies of field testing of airborne and impact insulation in multifamily residences," 2019.

[8] R. Kelly, "An Audio Demonstration of how Ears are More Sensitive to Changes in Low Frequency Noise For Instance Ground-Borne Noise from Tube Trains," presented at the ICSV 24, 2017.

[9] J. J. LoVerde and D. W. Dong, "Evaluation of field impact sound pressure levels as a function of tapping machine location," J. Acoust. Soc. Am., vol. 122, no. 5, pp. 2955-2955, Nov. 2007, doi: 10.1121/1.2942527.

[10] J. LoVerde and D. W. Dong, "Variations in impact sound level as a function of tapping machine position," J. Acoust. Soc. Am., vol. 141, no. 5, pp. 39293929, May 2017, doi: 10.1121/1.4988883.

[11] K. Larsson, C. Simmons, N. Amiryarahmadi, and X. Zhang, "Influence of tapping machine position on timber joist floors on the low frequency impact sound," presented at the INTER-NOISE 2012, New York, NY; United States, 2012.

[12] "ISO 16283-2 (2014), Acoustics - Field measurement of sound insulation in buildings and of building elements Part 2: Impact sound insulation," International Standards Organization, 2014. 